\title{
Una propuesta didáctica: Ecos mitológicos en la literatura y en la lengua española
} \author{
Languagel \\ ENGRACIA ROBLES REY \\ IES Mar Menor \\ MARÍA CONCEPCIÓN VÁZQUEZ MACIAS \\ IES Arié \\ España \\ engra200I@yahoo.es \\ concrazquez@hotmail.com
}

A teaching proposal: Echos of myths in Spanish Literature and

Resumen. Los mitos griegos tal y como nosotros los conocemos no pertenecen al tipo de historias tradicionales que alteran sus temas predominantes de acuerdo con los intereses cambiantes y las presiones sociales. Por el contrario, la mayoría de ellos están ya fijados en formas literarias relativamente inflexibles. Han dejado de ser parte de una cultura y de una sociedad de tipo plenamente tradicional. $Y$ se han convertido en parte del la literatura. La Metamorfosis pertenece a la época épicomitológica de Ovidio y tiene como denominador común las trasformaciones que sufrieron los héroes por la voluntad de los dioses. Temas y emblemas de la antigua mitología perviven así, envueltos en múltiples relatos y se prestan a ser recordados en la literatura una y otra vez.

Palabras clave: Mitología; literatura; Renacimiento; Garcilaso de la Vega; artes plásticas.
Abstract. Greek myths the way we know them do not belong to the type of traditional stories that alter their predominant themes according to changing interests and social pressures. On the contrary, most of them are already fixed in relatively inflexible literary forms. They have stopped being part of a culture and a society of a totally traditional type to become a part of the cannon. Metamorphosis belongs to the time of Ovid's mythological epic and shares with it a common denominator, transformations suffered by the heroes under the will of the gods. Themes and symbols of ancient mythology survive wrapped up in multiple accounts and lend themselves to be repeatedly revisited in literature again and again.

Key words: Mythology, literature, Renaissance, Garcilaso de la Vega, art.

\footnotetext{
${ }^{\text {I }}$ Para citar este artículo: Robles Rey, E. y Vázquez Macias, M. C. Una propuesta didáctica: Ecos mitológicos en la literatura y en la lengua española. Alabe 5, junio 2012 [http://www.ual.es/alabe]
} 
Magni interest quos quisque audiat quotidie domi; quibuscum loquatur a puero,quemmadmodum patres,paedagogi,matres etiam loquantur. Importa mucho lo que se oiga en casa, y con quienes se hable desde pequeños, $y$, del mismo modo como hablen los padres, los maestros y en especial las madres.

Cicerón, Brutus 55, 210.

\section{Introducción}

El planteamiento de la actividad didáctica que se propone está motivada por la importancia que debe concederse a la enseñanza de la cultura clásica de un modo menos tradicional y más directo.

El hecho de reducir el acercamiento del mundo clásico al aprendizaje de la lengua latina no parece suficiente en la enseñanza secundaria y, en Bachillerato, las referencias que se hacen del mundo clásico son bastante escasas, pues, salvo en la asignatura de historia en la que el alumno toma contacto con el mundo griego y romano, no se ahonda en demasía. Con el fin de despertar el interés por el pasado clásico, las actividades que se proponen para el curso $3^{\circ}$ de ESO y el objetivo general de esta propuesta no es otro que el de acercar a los alumnos a la mitología y a los hechos sobre la antigüedad grecorromana.

La elección de la literatura española y su relación con la mitología se debe fundamentalmente a que puede ser una actividad visible para el alumno, fácil de acercarse a ella, y permite enlazar con el mundo grecorromano además de que puede convertirse en una fuente de creatividad y se presta a intercambios interdisciplinares. Todo ello constituye un campo de cultivo ideal para la progresión de la actividad. Si existen ciertos objetivos bien definidos como contenidos que se realicen minuciosamente, el resultado será óptimo.

Decía Lucrecio que quiso escribir su De Rerum Natura en verso para hacer más ameno a los lectores un tema difícil "lo mismo que las madres dan a sus hijos la medicina amarga mezclada con miel con el fin de engañarlos para que se la tomen”; del mismo modo el profesorado debe utilizar todos los medios a nuestro alcance para conseguir que los alumnos aprendan algo de nuestras asignaturas.

Sin duda, la literatura occidental es una de las máximas deudoras de toda la tradición literaria de corte grecolatino. Este hecho no se dio de forma esporádica y puntual sino a través de todos los siglos aunque, es cierto, que se revalorizó en el Renacimiento considerablemente.

En nuestra literatura encontramos testimonios de la influencia dejada por las letras griegas y latinas tanto en la forma como en la temática. Uno de los temas clásicos a los que recurrieron los escritores posteriores fue el de la mitología.

La experiencia más educativa para nuestro alumnado consistirá en trazar las relaciones entre el mito y la lírica española del Renacimiento. Es necesario partir de la lectura de los textos propuestos y de la reflexión sobre el mito en cuestión y las características de la lírica de este periodo. 
Hay que tener en cuenta que para que el alumnado realice una lectura comprensiva requiere realizar inferencias sobre el texto, éstas vienen facilitadas por los conocimientos que poseen sobre el tema y sus experiencias anteriores de lecturas de los mitos clásicos. Serán un instrumento necesario para formar a alumnos dotados de los conocimientos y la cultura necesaria para desarrollar a alumnos competentes. Para ello la experiencia textual directa es muy importante.

Garcilaso de la Vega pertenece a la nómina de clásicos españoles que recurren a la corriente mitográfica para crear sus composiciones. En esta propuesta didáctica ofrecemos varias lecturas esenciales: el mito de Apolo y Dafne (perteneciente a la Metamorfosis de Ovidio), el soneto XIII y la Égloga III de Garcilaso de la Vega. La lectura se convierte en uno de los procesos de aprendizaje dado su gran valor para el enriquecimiento cultural y lingüístico.

Las literaturas modernas surgieron de la traducción y estudio de la literatura clásica. Se tomó de ellos prácticamente todo y se volvió a utilizar. Los temas y las formas se fueron innovando progresivamente entre los siglos XV y XVII. Durante este periodo, tuvo lugar la época más importante de la literatura europea. Por ello resulta imposible comprender a nuestros clásicos si no se tiene en cuenta la influencia que ejerció la literatura grecorromana.

Pero también es necesario destacar la influencia mitológica en la literatura hispánica moderna pues las narraciones mitológicas también han servido de inspiración a algunas obras. Temas y emblemas mitológicos perviven, envueltos en múltiples relatos y se prestan a ser recontados por la literatura moderna una y otra vez.

El final de la Odisea (Ulises llega a Ítaca bajo la apariencia de un mendigo al que sólo reconoce su perro. Penélope advertida de su llegada anuncia a los pretendientes que elegirá al que logre disparar una flecha. Ninguno lo consigue salvo Ulises que, tras darse a conocer, da muerte a los pretendientes) ha servido de inspiración a Ramón Pérez de Ayala. Los mitos de los que se sirve este autor recuperan aquí su doble función referencial: por una parte, la referencia a la propia narración y, por otra, la referencia a la realidad humana.

\section{Ecos mitológicos en la literatura}

\section{I.- Mitología y literatura grecorromana ${ }^{2}$ 2.I.I.- Mitología clásica y la literatura griega}

La literatura griega arcaica y clásica se ocupó esencialmente de relatar los mitos tradicionales. Estos mitos, narraciones heredadas por todo el pueblo, fueron modelados

\footnotetext{
${ }^{2}$ Gallardo, M. N. y García Otaola, A.M. (I994): Mitología clásica. Su proyección en el léxico y en la cultura. Madrid: Ediciones Clásicas. Se trata de una obra orientada a la práctica docente del aula y apoyada en la propia experiencia de los autores. En cinco unidades didácticas se presentan los principales dioses y héroes para que en la sexta realizar un recorrido por la presencia de la mitología en diversos campos de la cultura: Literatura, Arte, Cine, además hay una unidad en la que se trata el concepto de mito y se ofrecen las pautas de la docencia.
} 
literariamente por las palabras de los poetas.

Dioses y héroes míticos fueron materia fundamental de la poesía épica y del teatro trágico. Asimismo la poesía lírica tomó de éstos sus escenas. Hesiodo en el siglo VIII a. C., en el poema de la Teogonía, cuenta los orígenes del mundo y de los dioses. En el mismo siglo Homero narra, en la Iliada y la Odisea, las gestas de los héroes aqueos que lucharon en Troya y el regreso de Ulises a Ítaca. Los poetas tomaron el contenido de sus cantos de la tradición mitológica, transmitida de generación en generación, y ofrecieron su forma más bella y memorable a estos relatos que sus oyentes ya conocían. Los temas y figuras de la literatura clásica provienen del repertorio mítico. Para expresar esta relación con los mitos más antiguos, como Homero y Hesiodo, hablan de la inspiración divina que la Musa les ofrece.

Recordamos que tanto la Iliada como la Odisea comienzan con sendas invocaciones a la Musa: "Canta, diosa..."; "Cuenta, Musa..."

Y cuenta Hesiodo cómo a él se le aparecieron las Musas para encargarle la misión de cantar verazmente los comienzos de los dioses y del mundo.

\section{I.2 .- Mitología clásica y literatura romana}

La poesía latina siguió las huellas de los griegos en la épica y en el teatro clásico. Así los dramaturgos latinos que escribieron tragedias tomaron sus temas de los clásicos griegos, como es el caso de Séneca. Y los poetas épicos se inspiraron en la tradición helénica, como fue el caso de Virgilio con la Eneida.

Otros poetas, más tarde, han visto la mitología como un repertorio de historias fabulosas o dramáticas que la poesía podía rejuvenecer. Así Ovidio, versificador prolífico y hábil, recrea los relatos míticos de maravillosas transformaciones de dioses y héroes en su gran poema de las Metamorfosis, bella narración poética que constituye una verdadera "summa" de la mitología griega a la que une lo legendario de su país y que ha tenido numerosísimos ecos en la literatura posterior, en las artes plásticas, sobre todo, en la pintura a lo largo de muchos siglos, pues nunca dejó de preocupar a la imaginación de los artistas y de los escritores de la Edad Media.

Entre los relatos míticos destacan por su simbolismo y valor poético los que narran la transformación final de héroes y heroínas en otros seres vivos (plantas o animales) o en fuentes y ríos. Las leyendas que acompañan a estas metamorfosis han enriquecido continuamente el patrimonio artístico europeo desde el Renacimiento bajo la influencia de la obra Metamorfosis del poeta latino Ovidio (43.a.C-I7 d. C). Uno de los mitos narrados es el de Apolo y Dafne. El dios perseguía incansable a la ninfa hasta que ésta llegó a las orillas del río Peneo. Desesperada, la joven solicitó a su padre que la ayudara para escapar de los deseos de Apolo. Su padre accedió y la convirtió en el oloroso árbol del laurel. Desde ese momento se convirtió en el símbolo del dios. 


\section{2.- Mitología clásica y literatura española.}

La corriente mitográfica recorre la literatura española desde la Edad Media hasta la actualidad. Prueba de ello son las numerosas recreaciones y adaptaciones de los mitos en nuestra literatura, siendo los Siglos de Oro y el Barroco los periodos de mayor inspiración.

La Metamorfosis ha sido la obra que más influencia ha tenido, sirviendo de fuente de inspiración a escritores del siglo XVI como Garcilaso de la Vega y su soneto XIII, o Góngora que compuso Polifemo; otro ejemplo de fábula mitológica lo encontramos en Boscán en la Fábula de Leandro y Hero; Lope de Vega y Calderón de la Barca también encontraron en la corriente mitográfica de la época inspiración para escribir algunas de sus comedias.

De este breve resumen sobre las relaciones entre la literatura clásica y las letras hispánicas concluimos que el conocimiento de la literatura clásica y sus mitos es fundamental para una mejor comprensión de las obras de nuestros clásicos. Acercar la mitología a nuestros alumnos es una necesidad que deriva de la propia historia de la literatura para que este género deje de ser, parafraseando a Soto de Rojas, “paraíso cerrado para muchos" y convertirse en "jardines abiertos para otros".

\section{Objetivos}

Con esta unidad se pretende que los alumnos adquieran una visión de conjunto sobre la influencia de la mitología clásica en todo tipo de manifestaciones artísticas, sobre todo, en la Lengua castellana y Literatura, además de sensibilizar al alumno acerca de estudios clásicos, no muertos, sino enraizados en la sociedad, así como valorar el aprendizaje de la cultura del pasado para el conocimiento del presente. Por tanto, entre los objetivos y las competencias básicas que pretendemos alcanzar con el desarrollo de esta unidad didáctica se encuentran los siguientes:

Los objetivos generales de Lengua castellana y Literatura para la Enseñanza Secundaria Obligatoria.

Hacer de la lectura fuente de placer, de enriquecimiento personal y de conocimiento del mundo y consolidar hábitos lectores.

Comprender textos literarios utilizando conocimientos básicos sobre las convenciones de cada género, los temas y motivos de la tradición literaria y los recursos estilísticos.

\section{Los objetivos de la materia optativa de Cultura Clásica:}

Valorar la lengua latina como instrumento para la adquisición de otras lenguas antiguas y modernas.

Utilizar adecuadamente el manejo de fuentes antiguas diversas contrastando su contenido y forma con las modernas. 


\section{Los objetivos específicos de la etapa:}

Conocer y valorar el patrimonio artístico y cultural.

\section{Los objetivos específicos de esta unidad didáctica:}

Fomentar la lectura de textos mitológicos.

Conocer textos representativos de Garcilaso de la Vega, a partir de la lectura del mito de Apolo y Dafne.

Encontrar placer y sentido a la lectura como actividad de aprendizaje y entretenimiento. Reconocer la persistencia de la mitología en la literatura y en las obras de arte.

Ampliar el vocabulario con expresiones de origen latino.

\section{Competencias básicas:}

Competencia en comunicación lingüística: utilizar la lectura como fuente de información y entretenimiento.

Tratamiento de la información y competencia digital: saber extraer la información de textos leídos.

Competencia social y ciudadana: comprender que la lectura es una de las formas mejores y seguras de informarse.

Competencia cultural y artística: valorar y dar sentido a la lectura como actividad de ocio gratificante y enriquecedora.

Competencia para aprender a aprender: utilizar la lectura como medio de aprendizaje.

\section{Contenidos}

4.I.- Conceptuales

Los mitos: Apolo y Dafne.

La literatura renacentista en Garcilaso de la Vega.

Tópicos literarios.

\section{2.- Procedimentales.}

Lectura comprensiva de la traducción del mito de Apolo y Dafne de la Metamorfosis, de Ovidio.

Lectura comprensiva del soneto XIII y la Égloga III de Garcilaso de la Vega.

Relaciones entre el mito ovidiano y diversas representaciones pictóricas de éste.

Reconocimiento del mito de Apolo y Dafne en los textos de Garcilaso de la Vega.

Identificación de las características renacentistas en los textos trabajados. 


\section{3.-Actitudinales.}

Valoración positiva de la mitología como hecho que proporciona alguna de las claves interpretativas para comprender las producciones artísticas posteriores de nuestra literatura.

Gusto y valoración de la importancia de la lectura como modo de información, aprendizaje y entretenimiento.

Ser consciente de la relación interdisciplinar de las asignaturas del ciclo.

\section{Contenidos trasversales}

La lectura se va a acompañar de diversas obras pictóricas de grandes artistas que reproducen el mito de Apolo y Dafne para que el alumnado aprecie la relación entre las artes plásticas y el texto que sirve como fuente. Además de la conservación del patrimonio pictórico se intentará promover valores entre el alumnado como la valentía ante situaciones que implican peligro y la astucia como instrumento de inteligencia para solucionar problemas sin recurrir a la violencia. Relacionado con este último y dado el contenido de este mito con la educación sexual, se puede establecer un debate para contrastar los pareceres sobre la conducta sexual de los dioses.

\section{Metodología}

Esta unidad didáctica tiene como objetivo principal introducir a los alumnos de $3^{\circ}$ de la ESO en una visión más completa y madura de la literatura, de tal manera que estos conceptos y experiencias que aquí proponemos constituyen una aproximación que se puede ir completando y desarrollando en toda la enseñanza secundaria a través de proyectos. Con esta propuesta somos conscientes de que estamos iniciando una nueva etapa de desarrollo en la competencia literaria de nuestro alumnado, que los va a llevar de ser lectores meramente interpretativos e iniciarlos en una lectura más reflexiva.

Partiremos de la presentación de la unidad y realizaremos actividades de detección de sus ideas previas. Esperamos del alumnado una respuesta participativa y la realización de las actividades propuestas. Para ello hemos seleccionado las lecturas y los recursos más apropiados, teniendo en cuenta la mentalidad del alumnado de $3^{\circ}$ de la ESO y partir de aquello que resulta más familiar. A través de las muestras de paralelismos y contrastes entre la mitología clásica y el entorno del alumnado se consigue que los contenidos sean significativos. Trataremos de despertar su interés y curiosidad por los mitos, para ello partiremos de ejemplos relevantes y su relación con el empleo de numerosas expresiones comunes en el lenguaje; procuraremos darles todo el protagonismo para facilitar su aprendizaje y lograr su participación. 


\title{
7. Secuenciación
}

Las actividades que presentamos están ordenadas de menor a mayor grado de dificultad, comenzando por aquellas actividades que resultan más cercanas y motivadoras para los alumnos, para profundizar, posteriormente, en aquellas que desconocen y que contribuirán a mejorar sus conocimientos. En cuanto a la temporalización de las mismas se han propuesto cuatro sesiones, pero el ritmo de aprendizaje de los alumnos será el que determine el número de sesiones totales.

\section{Actividades}

\section{SESIÓN I}

\section{ACTIVIDADES DE INICIACIÓN Y EXPLORACIÓN INICIAL.}

Como es muy importante el factor sorpresa para la motivación, creemos que debe iniciarse esta actividad intentando que los alumnos conozcan qué son los mitos y cómo han llegado también al lenguaje habitual a través de diferentes expresiones hechas.

I. ¿Qué es un mito? ¿Qué es la mitología?

2. ¿Qué quiere decir que un cantante o un futbolista se ha convertido en un mito? colatina.

3. ¿Quién es quién? Juego sobre identificación de los dioses de la mitología gre-

Neptuno
Venus
Marte
Hades

diosa del amor.

dios de la guerra.

dios del mar.

dios de las tinieblas.

\section{ACTIVIDADES DE DESARROLLO.}

4. ¿Has oído alguna de estas expresiones? Seguro, porque las utilizamos con frecuencia en nuestra vida cotidiana. ¿Sabrías explicar su significado?

\author{
La música amansa a las fieras. \\ Eres una arpía. \\ Talón de Aquiles. \\ Manzana de la discordia. \\ Caballo de Troya. \\ Fue una Odisea. \\ Cantos de sirena.
}

Los alumnos intentarán explicar el significado de aquellas expresiones que co- 
nocen y tomaran nota de estas explicaciones. Después será preciso explicarles cuál es el origen de cada una de las expresiones, momento en el que comprobarán si sus interpretaciones iniciales han sido acertadas.

A continuación se proponen formas sinonímicas para que los alumnos formen parejas. Con esta actividad pretendemos que los alumnos tengan un conocimiento sobre la fraseología del español, reconozcan y empleen expresiones fijas de forma adecuada. Por otra parte, hay que tener en cuenta que el dominio de la fraseología contribuye al dominio de la competencia lingüística, especialmente la competencia comunicativa.

5. Ahora relaciona cada una de las expresiones anteriores con un sinónimo.

\begin{tabular}{|l|l|}
\hline EXPRESIONES MITOLÓGICAS & SINÓNIMOS \\
\hline La música amansa a las fieras & \\
\hline Eres una arpía & \\
\hline Talón de Aquiles & \\
\hline Manzana de la discordia & \\
\hline Caballo de Troya & \\
\hline Fue una Odisea & \\
\hline Cantos de sirena & \\
\hline
\end{tabular}

6. Lee el siguiente mito sobre Apolo y Dafne que escribió Ovidio en su Metamorfosis. Contesta a las siguientes preguntas.

¿Quiénes son los personajes? Indica una característica de cada uno de ellos.

Busca en el diccionario el significado de dios y Ninfa.

¿Qué quiere Apolo?

¿Cómo se siente Dafne? ¿Qué decisión toma?

¿Cuál es la reacción de Apolo ante la transformación de Dafne?

¿Qué consecuencias tiene esa reacción?

Aquí se propone como ejemplo la lectura de la historia de Dafne, perteneciente a 
la obra de Ovidio la Metamorfosis, y la lectura del soneto XIII de Garcilaso. Hemos elegido este relato de Ovidio (Met, I ,452-567) porque es el más extenso y detallado de este mito y el que más influencia ha tenido en la literatura posterior española. El amor de Apolo a Dafne tiene su origen en la venganza de Cupido, pues Apolo estaba tan orgulloso de su victoria sobre Pitón que, al aparecer por allí Cupido, armado con flechas, se ofendió y le regañó diciendo que no le cuadraba llevar tales armas, a lo que el dios del amor responde sacando dos flechas de su aljaba, con una de oro dispara a Apolo y con una de plomo ahuyenta el amor a Dafne y de este modo en ambos se producen sentimientos contrarios.

A Dafne la describe como amante de las selvas, cazadora émula de Diana (v46o) que rehúye el amor (v48o), su padre le había concedido el don de permanecer virgen como hiciera Júpiter con Diana.

El enamoramiento de Apolo lo detalla Ovidio (vv 490-502). Se enamora de ella, arde de amor y contempla con admiración su belleza: sus cabellos desaliñados, sus brillantes ojos, su boca, sus manos y brazos e imagina otras bellezas ocultas ( $\mathrm{vv} 5 \mathrm{OO}-5 \mathrm{O}$ ). Según Ovidio (v 504-505), la ninfa huye asustada, y éste trata de impedírselo; comienza un largo elogio de sí mísmo. En este punto, Ovidio recurre a la descripción mediante símiles: la ninfa huye como la cordera del lobo o la cierva del león. A punto de ser alcanzada pide ayuda a su padre.

Ovidio es único para recrear la trasformación de Dafne, llena de plasticidad: su cuerpo se ve envuelto por una fina corteza, sus cabellos se trasforman en hojas, sus brazos en ramas y sus pies se quedan fijos convertidos en raíces; su cabeza en la copa de un árbol. Apolo la alcanza en el momento de la metamorfosis, abrazándola, pronuncia unas palabras finales en las que otorga a este árbol varios honores y privilegios.

\section{SESIÓN 2.}

\section{ACTIVIDADES DE DESARROLLO Y COMPLEMENTARIAS.}

Como hemos expuesto en el apartado de los contenidos transversales, proponemos que el alumnado aprecie la relación entre las artes plásticas y el texto que sirve como fuente. Para ello utilizamos dos grabados de Agustino Veneziano y la obra escultórica de Lorenzo Bernini.

7. Observa los siguientes grabados.

¿Con qué partes del mito de Apolo y Dafne lo relacionas?

Describe las sensaciones que te transmiten los grabados.

¿Crees que los dioses han de ser obligatoriamente fuertes y poderosos, y las diosas bellas? En grupos, seleccionad personajes famosos que se ajusten a estos prototipos y otros que no. Después señalad por qué son conocidos. 
Con la lectura del soneto XIII de Garcilaso de la Vega apreciamos la gran emoción artística que suscita en él la mitología y cómo el mito de Apolo y Dafne le sirve de ejemplo para expresar su propio estado amoroso. El mismo Garcilaso podría compararse con Apolo reflejando además el código petrarquista:

Apolo: amante no correspondido/poeta de inspiración platónica.

Dafne: amada desdeñosa, inalcanzable.

Para introducir al alumnado en la comprensión del tópico literario renacentista "descriptio puellae" recurrimos a la enorme plasticidad con la que Garcilaso describe el momento de la transformación en este soneto.

8. A continuación lee el siguiente soneto de Garcilaso de la Vega. Contesta a las siguientes preguntas.

A Dafne ya los brazos le crecían,

y en luengos ramos vueltos se mostraban;

en verdes hojas vi que se tornaban

los cabellos que al oro oscurecían. 4

De áspera corteza se cubría

los tiernos miembros, que aún balbuciendo estaban;

los blancos pies en tierra se hincaban

y en torcidas raíces se volvían

Aquel que fue la causa de tal daño,

a fuerza de llorar, crecer hacía

el árbol que con lágrimas regaba. II

¡Oh miserable estado, oh mal tamaño!

Que con llorarla crezca cada día

la causa y la razón por que lloraba! I4

¿Qué le ocurre a Dafne?

¿Quién es el causante? Señala los versos que te han permitido averiguarlo.

¿En qué texto se inspira Garcilaso para componer este soneto?

¿Qué modalidad textual predomina el soneto?

En este soneto encontramos el tópico literario “descriptio puellae”, característico del Renacimiento. Explica en qué consiste el tópico y localiza los versos que hacen referencia a él. 
9. Observa ahora la escultura de Bernini y algunos grabados sobre este mito. ¿Crees que Garcilaso pudo inspirarse en alguna pintura para componer este soneto? Razona tu respuesta.

\section{SESIÓN 3}

\section{ACTIVIDADES DE DESARROLLO.}

Después de trabajar la comprensión del mito ovidiano a través de la lectura, de relacionar esa metamorfosis que nos relata Ovidio y sus representaciones gráficas, así como descubrir la influencia de este mito en la obra de Garcilaso; los alumnos pueden enfrentarse a la lectura fragmentaria de la Égloga III del poeta español y descubrir las similitudes que existen entre ésta, el soneto XIII y el mito de Apolo y Dafne.

Io. Lee el siguiente fragmento de la Égloga III (vv I45-I67) de Garcilaso de la Vega. Contesta a las siguientes preguntas.

Dinámene no menos artificio mostraba en la labor que había tejido, pintando a Apolo en el robusto oficio de la silvestre caza embebecido. Mudar luego le hace el ejercicio la vengativa mano de Cupido que hizo a Apolo consumirse en lloro después que le enclavó con punta de oro.

Dafne con el cabello suelto al viento, sin perdonar al blanco pie corría por áspero camino, tan sin tiento que Apolo en la pintura parecía que, porque ella templase el movimiento, con menos ligereza la segura. Él va siguiendo, y ella huye como quien siente al pecho el odioso plomo.

Mas a la fin los brazos le crecían, y en sendos ramos vueltos se mostraban.

Y los cabellos que vencer solían al oro fino, en hojas se tornaban en torcidas raíces se extendían los blancos pies, y en tierra se hincaban; llora el amante, y busca el ser primero, besando y abrazando aquel madero.

¿Te ha resultado comprensible la lectura? ¿Por qué? 
Explica el contenido de estas estrofas.

¿Qué similitudes encuentras con el soneto XIII de Garcilaso?

¿En quién crees que se inspiró Garcilaso para componer los textos que has leído?

Los alumnos pueden apreciar cómo el canon de belleza renacentista está aún vigente en nuestra sociedad a través de los textos seleccionados.

II. ¿Qué características presenta Dafne como modelo de mujer en la Metamorfosis y en los fragmentos leídos de Garcilaso de la Vega? teriores?

I2. ¿Existen semejanzas entre los modelos de mujer actual y los de las épocas anSESIÓN 4 .

\section{ACTIVIDADES DE REFUERZO Y AMPLIACIÓN.}

I3. Ahora elabora una noticia basándote en el mito de Apolo y Dafne. Realiza los cambios necesarios para adaptar los hechos a la actualidad. No olvides seguir la estructura de la noticia: titular, entradilla y cuerpo.

I4. Imagina y representa la conversación que pudieron mantener Apolo y Dafne.

I5. Busca información sobre Ovidio y Garcilaso de la Vega para completar la siguiente ficha.

\begin{tabular}{|c|c|c|}
\hline & OVIDIO & GARCILASO DE LA VEGA \\
\hline ÉPOCA & & \\
\hline OBRAS IMPORTANTES & & \\
\hline $\begin{array}{c}\text { IMPORTANCIA DE SUS } \\
\text { OBRAS }\end{array}$ & & \\
\hline
\end{tabular}




\begin{tabular}{|l|l|l|}
\hline \multicolumn{1}{|c|}{ SOY CAPAZ DE: } & SI & NO \\
\hline $\begin{array}{l}\text { Reconocer la importancia de la } \\
\text { literatura latina }\end{array}$ & & \\
\hline Comprender textos antiguos & & \\
& & \\
\hline
\end{tabular}

\begin{tabular}{|l|l|l|}
\hline $\begin{array}{l}\text { Utilizar expresiones procedentes } \\
\text { del lenguaje mitológico }\end{array}$ & & \\
\hline $\begin{array}{l}\text { Reconocer la influencia de la } \\
\text { mitología en la pintura }\end{array}$ & & \\
\hline Identificar los tópicos literarios & & \\
\hline $\begin{array}{l}\text { Reconocer la presencia de } \\
\text { elementos mitológicos en textos } \\
\text { de Garcilaso. }\end{array}$ & & \\
\hline
\end{tabular}

\section{ACTIVIDADES DE EVALUACIÓN.}

I5. Actividades de autoevaluación.

\section{Atención a la diversidad}

Al trabajar esta unidad podremos encontrar disparidad de conocimientos y experiencias previas sobre lectura y literatura. Para aquellos alumnos menos motivados y capaces le vamos a prestar el refuerzo que necesiten para comprender y realizar las actividades, así como el trabajo cooperativo con sus compañeros. Los alumnos que presenten un mayor interés realizarán las actividades de ampliación como la lectura de otros mitos y su posterior influencia en la literatura castellana. 


\section{Io. Materiales y recursos}

Emplearemos los siguientes materiales y recursos en el desarrollo de la unidad didáctica:

Imágenes de las obras de arte como apoyo a los textos: grabados de Lorenzo Veneziano y la escultura de Bernini.

Texto sobre el mito de Apolo y Dafne perteneciente a la Metamorfosis de Ovidio. Adaptación de Agustín Sánchez Aguilar. Vicens Vives. Barcelona. 2010.

Selección de textos de Garcilaso de la Vega: soneto XXIII y la Égloga III (vv I45-I67).

La pizarra digital o el proyector para el visionado de las imágenes de las obras de arte.

\section{Evaluación}

\section{II.I.- Instrumentos de evaluación}

Vamos a utilizar una serie de instrumentos y procedimientos de evaluación que detallamos a continuación:

Observación directa y el cuaderno del profesor.

Cuaderno de trabajo del alumno, la realización de las actividades propuestas y la calidad de las mismas.

Participación en clase.

Encuesta de autoevaluación.

Realización de una prueba como ejercicio de evaluación sumativa que consistirá en la lectura de un poema renacentista y comentario sobre sus características, rasgos estilísticos, la presencia de elementos mitológicos y el tema.

\section{II.2.- Criterios de evaluación}

Distinguir elementos mitológicos en textos renacentistas y señalar sus características.

Utilizar correctamente expresiones hechas de origen latino.

Entender y valorar las manifestaciones poéticas de nuestra literatura.

Relacionar las constantes estéticas y los ideales de belleza en la literatura, la pintura y la escultura.

\section{I2. Conclusión}

La literatura occidental es una de las deudoras de toda la tradición literaria de corte grecolatino. Este hecho no se dio de forma esporádica y puntual sino a través de todos los siglos, aunque es cierto que se revalorizó considerablemente desde el Renacimiento. 
Encontramos en nuestra literatura numerosos testimonios de la influencia dejada por las letras griegas y romanas tanto en la temática como en la forma. Uno de los temas clásicos a los que más recurrieron los escritores posteriores fue el de la mitología.

Con esta unidad didáctica planteamos una aproximación a la literatura clásica y española a partir de la lectura de textos representativos y su relación con la pintura y la escultura.

La animación a la lectura de los clásicos en el aula facilita trabajar la propia lectura como uno de los procesos de aprendizaje dado su gran valor para el enriquecimiento cultural y lingüístico, siendo, por otra parte, una de las principales vías para aprender. 


\section{Bibliografía}

- Castro Jiménez, Ma Dolores. (I990): "Presencia de un mito ovidiano: Apolo y Dafne en la literatura española de la Edad Media y el Renacimiento". Cuadernos de Filología clásica, no 24. Págs. 195-222.

- Escobar, Francisco Javier. (200I): "El tema de Apolo y Dafne en Garcilaso de la Vega: Paralelos pictóricos”. Calamus Renascens $\left(\mathrm{n}^{\circ}{ }_{2}\right)$. Alcañiz-Teruel-Cádiz: Instituto de Estudios Humanísticos. Págs 223-238.

- Graves, Robert. (i986): Dioses y héroes de la antigua Grecia. Barcelona: Lumen.

- Grimal, P. (1984): Diccionario de mitología Griega y romana. Barcelona: Paidós.

- Hernández Lucas, Ma Teresa. (i99o): Mitología Clásica. Teoría y práctica docente. Ediciones Clásicas.

- Humbert, J. (1982): Mitología griega y romana. Madrid: Gustavo Gili.

- Ruiz de Elvira, A. (1982): Mitología Clásica. Madrid: Universidad de Alcalá de Henares.

- Tejero Robledo, Eduardo. (i997): "El retorno de los mitos. Mitología. Literatura. Transferencia didáctica” en Didáctica, nº 9. Págs. 279-3Io. Madrid: Universidad Complutense de Madrid.

- Vega, Garcilaso de la. (1983): Obras completas. Barcelona: Planeta. 